\title{
SIMULTANEOUS PERFORATION OF BENIGN GASTRIC AND DUODENAL ULCERS
}

By H. D. W. Powell, F.R.C.S. Senior Orthopaedic Registrar, Salford.Group of Hospiials; late Orthopaedic Registrar, St. Giles' Hospital, Camberwell

Finney (1900) stated that in 20 per cent. of patients with a perforated peptic ulcer, more than one perforation occurred. Fifty years later Aird gives a figure of less than I per cent.; both report multiple perforations of a single large ulcer. Yet, while every volume of the 'Index Medicus' contains hundreds of references to peptic ulceration, reports of double perforations are rare.

Masson and Simon (1927) collected thirty-three case reports; the diagnosis was made usually at autopsy-rarely at operation, and never clinically,

The mortality was high. Only eighteen patients came to operation and the only four who recovered were those in whom both perforations were closed.

Austin (1938) reported a man of twenty-seven, with simultaneous perforations of low gastric and high duodenal ulcers, who survived closure of both.

Livingstone (1950) also reported the successful closure of simultaneous gastro-jejunal and jejunal perforations.

Concomitant gastric and duodenal ulcers have been studied in recent papers by Johnson (1955) and Feldman (1953); both of whom emphasized that their co-existence is by no means uncommon. Feldman collected figures from twenty-five authors; the average percentage for double ulceration being about ten. He believed that the duodenal ulcer occurred first and the gastric ulcer later.

Johnson holds similar views and stresses that many have gross pyloric stenosis. He found double ulceration in 9 per cent. of his surgical series of 313 patients.

\section{Case Report}

History.-A. S.-a heating engineer, aged 48, was admitted on Christmas Eve, 1955. He gave a history of twelve years' indigestion helped by 'powders.' He had repeatedly refused his own doctor's recommendation of hospital investigation and treatment. For one month prior to admission he had had severe indigestion and persistent vomiting. Acute, severe pain ensued about 3 p.m. on the day of admission;-

Examination revealed an emaciated man, who looked far older than his stated age; presenting the classical picture of perforated peptic ulcer. So grave was his appearance that his own doctor had suggested the possibility of a perforated gastric carcinoma.

Operation.- Under general anaesthesia the abdomen was opened by a right upper paramedian incision, revealing gross soiling of the upper quadrant and a small anterior perforation in the first part of the duodenum. From this a fan-shaped area of inflammatory exudate spread down into morrison's pouch. Immediately distal to the oesophago-gastric junction a firm mass was palpated with a second and larger perforation, from which another and entirely separate area of inflammatory exudate spread distally. So firm was this mass that it was thought to be a gastric carcinoma.

The duodenal perforation was closed, but closure of the gastric perforation was technically impossible without enlarging the incision extensively and this was considered unjustifiable in view of the patient's general condition. A high jejunostomy was therefore performed and a right flank stab drain was led up to the site of the gastric perforation.

His post-operative course was complicated by repeated epileptic fits which, despite heavy anticonvulsive sedation, ultimately culminated in a condition of status epilepticus. Despite this, his enterostomy feeding worked without difficulty, and for a time his nutritional state improved.

He finally succumbed on January 16 , twentythree days after operation.

\section{Post-Mortem (Dr. E. A. Bailey)}

Revealed a small left anterior subphrenic abscess with a number of coils of small intestine moderately firmly adherent to one another. The gastric perforation, one centimetre in diameter, remained 
unclosed, and was partly adherent to the underside of the liver. The duodenal perforation remained closed. There was considerable stenosis of the pylorus with consequent gastric dilatation. Neither ulcer showed any evidence of malignant change.

Subsequent histological examination of the stomach and related lymph glands showed no evidence of malignancy. (Dr. L. W. Proger).

\section{Summary}

A further case is briefly reported of simultaneous perforations of gastric and duodenal ulcers; the gastric ulcer occurring in the upper one inch of the stomach. No similar case has been found in the literature.

This unfortunate patient once again exemplifies the need to bear in mind the possibility of more than one perforation being present.

\section{Acknowledgements}

I wish to thank: Mr. Iain Matheson for permission to publish this report; Dr. E. A. Bailey for the post-mortem report; and Dr. L. W. Proger for further histological examination.

\section{BIBLIOGRAPHY}

AIRD, I. (1949), 'Companion in Surgical Studies,' Livingstone, Edinburgh.

AUSTIN, W. E. (1938), Brit. F. Surg., 26, 387.

FELDMAN, M. (1953), Gastroenterology, 23, 304.

FINNEY, J. T. (1900), Ann. Surg., 32, 1.

JOHNSON, H. D. (1955), Lancet, I, 266.

LIVINGSTONE, D. J. (1950), Brit. $f$. Surg. 38, 24I.

MASSON, J. C., and SIMON, H. E. (r927), Minn. Med. 10, 289.

\section{'CORTISPORIN'}

'Cortisporin,' a new antibiotic ointment for skin and eye infections, is now available from Burroughs Wellcome \& Co. Each gramme contains 'Aerosporin' brand Polymyxin B sulphate 5,000 units, bacitracin 400 units, neomycin sulphate $5 \mathrm{mg}$., and hydrocortisone (free alcohol) $5 \mathrm{mg}$. The ointment has an antibacterial range greater than that of any single antibiotic and is successful even against Pseudomonas pyocyanea and Proteus vulgaris. Skin sensitization and bacterial resistance are unlikely, and there is no likelihood of cross-sensitization or cross-resistance to other antibiotics. A further feature of the ointment is that it reduces inflammation and allergic reactions. 'Cortisporin' brand ointment is issued in tubes of $10 \mathrm{~g}$. with special nozzle. Burroughs Wellcome \& Co., Euston Road, N.W.r.

\section{' EPITONE,}

Boots Pure Drug Co. Ltd. have announced that the formula of 'Epitone' has been improved in certain respects and the new formula is now being supplied against all orders.

The new product is distinguished by the words
'Improved Formula' on the pack and is available in bottles of 8 and $16 \mathrm{fl}$. oz. only. The 8o-oz. pack of 'Epitone' is discontinued.

Boots Pure Drug Co. Ltd. announce the availability of 'Secretin' and 'Pancreozymin' in pure and stable form. These hormones are normally produced in the duodenal mucosa during the cycle of digestive processes, and they are used clinically as diagnostic aids in disorders of the pancreas and gall-bladder. 'Secretin' is supplied in $10 \mathrm{ml}$. rubber-capped vials of 100 units and 'Pancreozymin' in $25 \mathrm{ml}$. rubber-capped vials of Ioo units, both preparations being in the form of powder. In this form, they retain their activity almost indefinitely at room temperature or below. Detailed literature available on request.

\section{' DELTA-STAB'}

Boots Pure Drug Co. Ltd. announce the availability of 'Delta-Stab' (prednisolone) as follows:

Basic N.H.S. Price I mg. $5 \mathrm{mg}$.

Bottle of 30 tablets s. d. s. d.

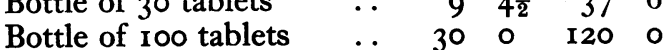

Bottle of 500 tablets $\quad . \quad 145 \circ 580 \quad 0$

CoRrection.-Ozing to a printer's error in our April issue the Summer Courses of Instruction in the Principles and Practice of Homoeopathy for Medical Practitioners and Senior Students at the Royal London Homoeopathic Hospital was advertised as beginning on Tuesday, April 9, whereas the opening date should have read Tuesday, April 30. 